\title{
Pulse Rocket Performance
}

\author{
J. W. Hadley
}

\section{RECEIVED \\ JAN 311997 \\ OSTI}

\section{MASTER}

August 13, 1963

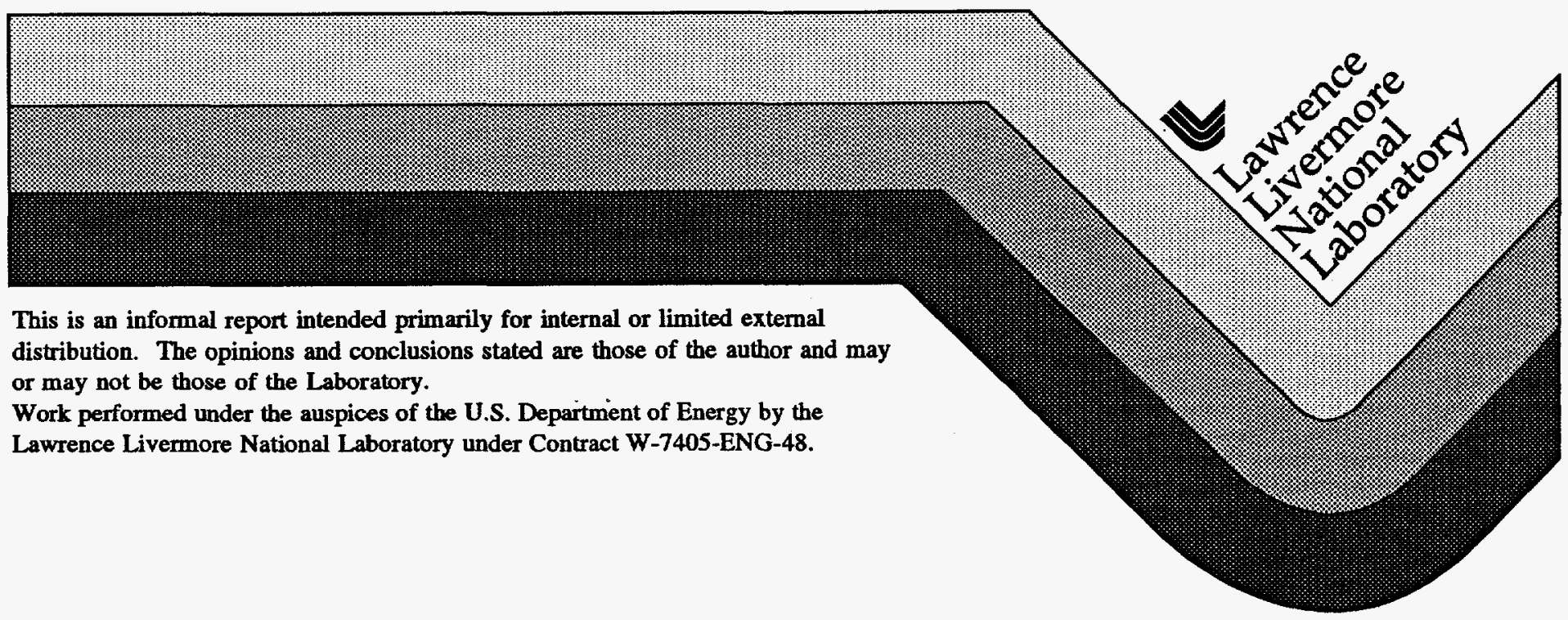




\section{DISCLAIMER}

This report was prepared as an account of work sponsored by an agency of the United States Government. Neither the United States Government nor any agency thereof, nor any of their employees, make any warranty, express or implied, or assumes any legal liability or responsibility for the accuracy, completeness, or usefulness of any information, apparatus, product, or process disclosed, or represents that its use would not infringe privately owned rights. Reference herein to any specific commercial product, process, or service by trade name, trademark, manufacturer, or otherwise does not necessarily constitute or imply its endorsement, recommendation, or favoring by the United States Government or any agency thereof. The views and opinions of authors expressed herein do not necessarily state or reflect those of the United States Government or any agency thereof. 


\section{DISCLAIMER}

Portions of this document may be illegible in electronic image products. Images are produced from the best available original document. 


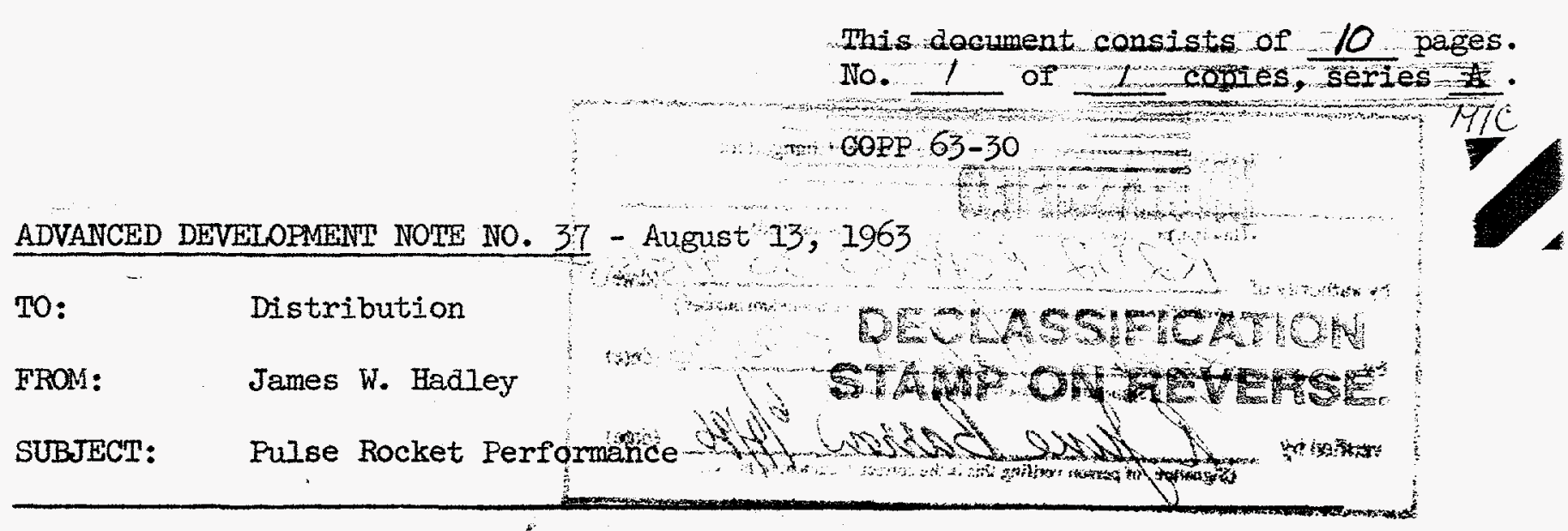

This note derives some relationships between the various parameters describing the nuclear pulse rocket, and gives numerical examples of performance attainable under the assumption of a fixed chamber temperature.

\section{Introduction}

The pulse rocket to be analysed here is a device to be designed for optimum performance in taking a fixed payload of about 50 tons from earth orbit through a round trip to Mars. The vehicle consists of the payload, which includes crew, shielding, life support equipment, controls, etc.; of some additional hardware such as exhaust nozzle, pumps, and the like, whose mss really depends on other deslgn variables but w111 be treated as part of the fixed mass here; of propellant material to be expelled for momentum transfer; of propellant tankage; of a large and strong chamber or pressure shell in which discrete charges of propellant are raised to high temperature; and of a supply of nuclear energy source devices, one of which is to be introduced into the chamber with each propellant charge. This nuclear material could take the form of fairly conventional nuclear weapon-like devices of very small yield, or might be entirely different.

The analysis given here emphasizes the effect of varying the proportion of propellant material added to each charge. Maximum energy per unit mass, maximum exhaust velocity, and hence maximum propulsion efficiency, for a fixed value of energy per charge, are attained by not adding any propellant material to that necessary for the nuclear energy producticn. The latter can reafonably be suppesed to consist mainly of high explosive naterlal. Onfortuastely th1s would also result in very 
high chamber temperatures, so that the addition of a supplementary propellant material of low atomic weight will probably be necessary. If one is limited to a given chamber temperature, then the highest specific impulse is attained by adding large amounts of hydrogen. At least some hydrogen or other material in addition to the nuclear device appears to be needed for pressure vessel and nozzle cooling.

In order to be able to use simple analytical relationships here, the hot gas in the pressure vessel is treated as a gamma-law gas, and the effect of varying amounts of dissociation on the energy-pressure relationship is ignored. The effect of pressure vessel size and gas temperature on the welght of the vessel is thus omitted entirely. This relationship is illustrated in a parallel study described by T. Stubbs. ${ }^{1}$ 2. Analysis

The system to be analysed will be described in terms of the following variables:

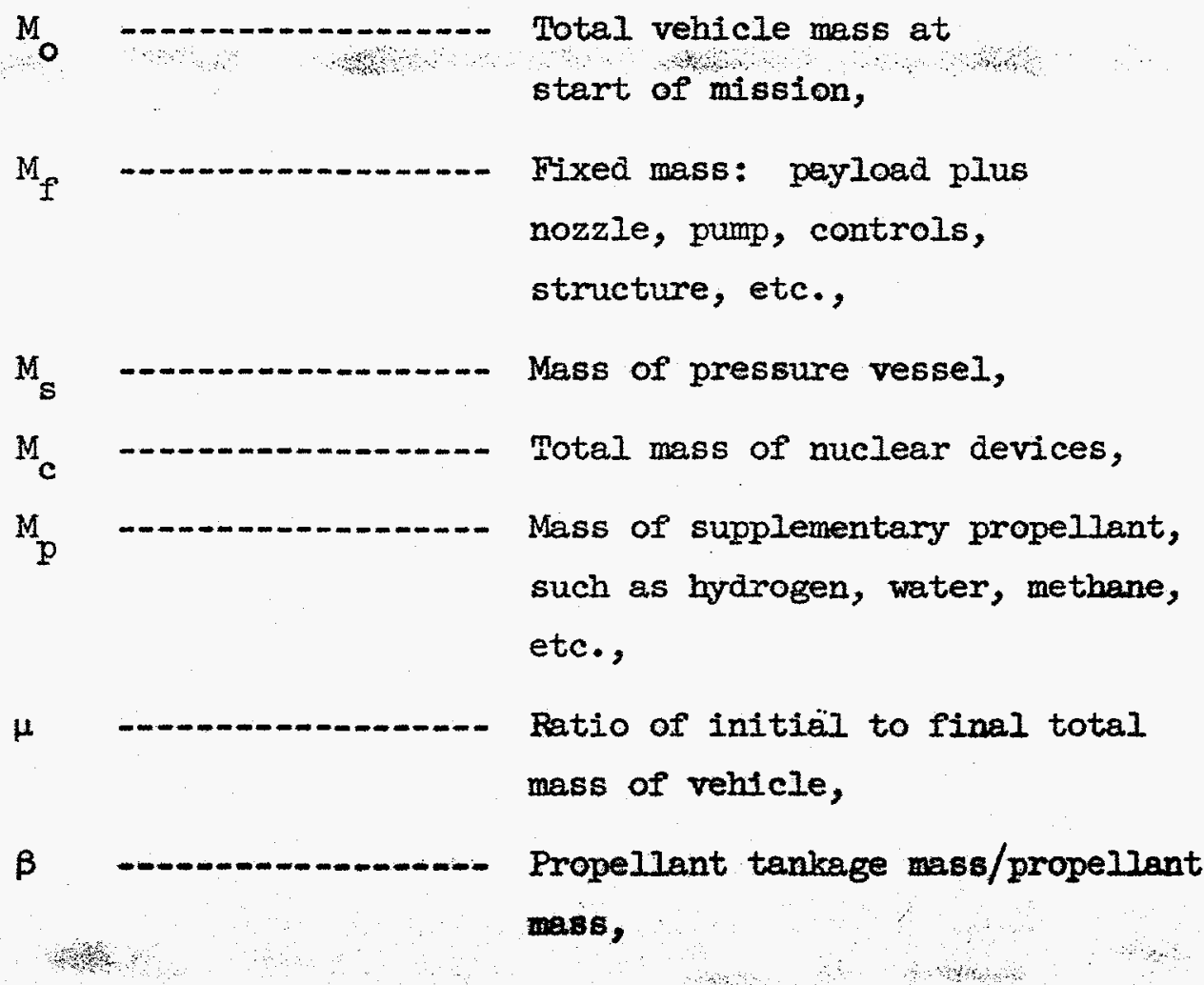

1. T. Stubbs, ADN No. 36 . 
$\Delta \mathrm{v}$

$v_{\text {ex }}$

g

$I_{\operatorname{sp}}$

H

$\mathbf{Y}$

N

$\epsilon$

$\omega$

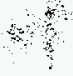

$\mathbf{T}$

M

$x$

$x$
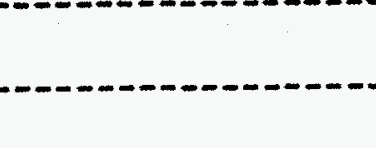
mission,
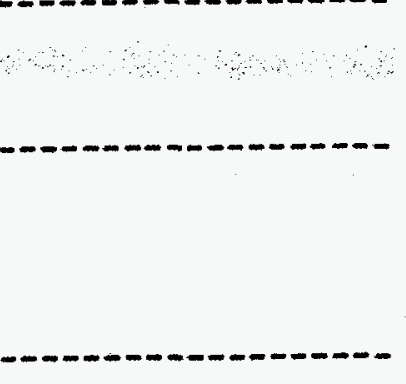

mission,

Exhaust velocity,

Acceleration due to gravity

$\left(980 \mathrm{~cm} \cdot \mathrm{sec}^{-1}\right)$

Specific impulse,

Initial enthalpy per unit mass of propellant mixture in pressure vessel,

Energy yield of each nuclear device,

Number of charges used throughout

Mass of a single complete nuclear device,

Ratio of pressure vessel mass to energy yield per charge,

Mass fraction of supplementary propellant (e.g. hydrogen) in the total propellant mixture,

Initial steady pressure in the pressure vessel, after decay of shocks, etc.

Injtial temperature of propellant
mixture,

Representative atomic weight of material comprising the nuclear device.

These variables are related by number of equations, which 
The initial total mass is the sum of its component parts:

1)

$$
M_{0}=M_{f}+(I+\beta) M_{p}+M_{s}+M_{c}
$$

The initial to final total mass ratio is given by the familiar rocket equation:

2)

$$
\frac{M_{o}}{M_{0}-M_{p}-M_{c}}=\mu=e^{\frac{\Delta v}{g I}}
$$

The ideal exhaust velocity is equal to the square root of twice the specific enthalpy in the chamber; as an estimate of the average effective value a.lowing for pressure decay during a pulse, for incomplete expansion, and for incomplete recovery of dissociation energy, we will use $70 \%$ of that value. This reduction is believed to be about right, perhaps a little on the pessimistic side. Separate studies will produce a better number.

$$
\text { 3) } \quad I_{\mathrm{sp}} \equiv v_{\mathrm{ex}} \simeq 0.7 \sqrt{2 \mathrm{H}} \text {. }
$$

We vill assume that the supplementary propellant is hydrogen. In the pressure-temperature range of interest to us, the specific enthalpy is equal approximately to 1.2 times the energy per unit mass,

$$
H \simeq 1.2 \frac{Y^{\prime} N}{M_{p}^{\prime}+M_{c}^{\prime}} \text {, }
$$

or putting $Y$ and $M_{p}, M_{c}$ into convenient units of tons TNT equiv. and tons mass, with $H$ in c.g.s. units,

$$
\text { 4) } \quad \mathrm{H}=5.29 \times 10^{10} \frac{\mathrm{YN}}{M_{p}+M_{c}} \text {. }
$$

The total mass of nuclear devices is $\mathrm{N}$ times the mass per unit,

5)

$$
M_{e}=\mathrm{N} \epsilon
$$

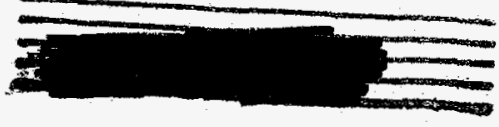


The pressure vessel mass is assumed to vary in constant proportion to the energy yield per charge ${ }^{2,1}$ :

6) $\quad M_{S}=\varphi Y$

We have now six equations and eight unknowns describing the system. The unknowns are $M_{0}, M_{p}, M_{s}, M_{c}, I_{s p}, H, Y$, and $N$. Specification of any two of these will then serve to define the system completely. Let us now reduce the system of equations to a single one relating $M_{0}$ to $I_{s p}$ and $M_{p}$. By combining (3) and (4), we obtain

7)

$$
\frac{\mathrm{YM}}{\mathrm{M}_{\mathrm{p}}+\mathrm{M}_{\mathrm{c}}}=19.3\left(10^{-6} \mathrm{~g} \mathrm{I}_{\mathrm{sp}}\right)^{2} \text {, }
$$

and then with (5) and (6) we have

8)

$$
M_{s}=19.3\left(10^{-6} I_{s p}\right)^{2} \frac{\epsilon \omega\left(M_{p}+M_{c}\right)}{M_{c}} .
$$

Rearrangling (2) gives

9)

$$
M_{c}=\frac{\mu-1}{\mu} M_{o}-M_{p} \text {, }
$$

and finally, substituting (8) and (9) into (1) leads to

10)

$$
M_{0}=\mu\left[M_{f}+\beta M_{p}+\frac{19.3\left(10^{-6} g I_{s p}\right)^{2} \in \omega}{1-\frac{\mu M_{p}}{(\mu-1) M_{0}}}\right]
$$

In Section 1, the statement was made that minimizing the value of $M_{p}$, for fixed $Y$, would give maximum propulsion effletency (1.e. minimum $M_{0}$ ) by producing meximum $I_{8 p}$. How we can see from inspection of equation (10)

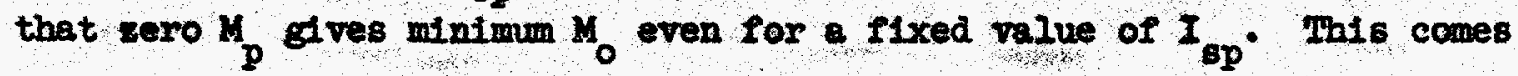

2. R. FOX, ADN Ho. 2 (COPP-1972), Jan. 7, 1957. 
about through elimination of tankage weight and minimization of the pressure vessel weight (fixed $I_{s p}$ and low mass implies low yield, hence low vessel weight).

$$
\text { Setting } M_{p}=0 \text { in equation (10) gives: }
$$

11)

$$
M_{0}=e^{\frac{\Delta v}{g I_{s p}}}\left[M_{f}+19.3\left(10^{-6} g I_{s p}\right)^{2} \in \omega\right],
$$

and to minimize $M_{0}$, we differentiate with respect to $I_{s p}$ and set the result equal to zero, giving

$$
0=\frac{\Delta v}{g}\left[\frac{M_{f}}{I_{s p}^{2}}+19.3 \times 10^{-12} g^{2} \in \omega\right]-38.6 \times 10^{-12} \mathrm{~g}^{2} \in \omega I_{s p} .
$$

Now take

$$
\begin{aligned}
& \Delta v=60,000 \mathrm{ft} \cdot \mathrm{sec}^{-1} \\
& M_{f}=62.5 \text { tons } \\
& \epsilon=0.025 \text { tons }(50 \mathrm{lb.}) \\
& \omega=21.3 \text { tons/ton TNT equiv. }
\end{aligned}
$$

and obtain

$$
\begin{aligned}
& I_{s p}=2177 \mathrm{sec} . \\
& M_{0}=260 \text { tons }(520,000 \mathrm{Ib} .) .
\end{aligned}
$$

This system, using no propellant mass except that of the nuclear devices themselves, is an unrealistic one, since clearly at least some additional material will be pumped through the pressure shell as a coolant, and also since no attention has been paid to temperature. Reference to equation (3) glves $H=1.1 \times 10^{5} \mathrm{cal} \cdot \mathrm{g}^{-1}$, and if we assume that the nuclear device is a weapon-like implosion system with most of the mass being TMT, with average (dissociated) atomic weight $\sim 10$, then the temperature is in the neighborhood of $200,000^{\circ} \mathrm{K}$. 
Being now satisfied that a substantial amount of low-atomicweight additive is necessary, we will look for a more reasonable estimate of performance. Iet us assume that the chamber temperature must be limited to some fixed maximum value $T$. We will then study performance as a function of the one remaining degree of freedom in the system.

The contents of the rocket chamber at the beginning of each pulse cycle will consist of material with a mass fraction $(X)$ of lowatomic-weight supplementary propellant, and a mass fraction $(X-1)$ of residue from the nuclear device, which we will treat as a monatomic gas of atomic weight $M$. The enthalpy of the device residue will therefore be $\sim \frac{5}{2} \mathrm{RT} \sim 5 \mathrm{I} \mathrm{cal} \cdot \mathrm{mole} \mathrm{e}^{-1}$ or $5 \mathrm{~T} / \mathrm{M} \mathrm{cal} \cdot \mathrm{g}^{-1}$. The enthalpy (cal $\cdot \mathrm{g}^{-1}$ ) of the supplementary propellant will be denoted by $h_{p}$. For $g I_{s p}$ in c.g.s. units, we can write, again with a $70 \%$ recovery factor,

$$
\begin{aligned}
g I_{s p} & =0.7 \overline{(2 \mathrm{H})^{1 / 2}} \\
& =6.40 \times 10^{3}\left[X \sqrt{h_{p}}+(1-X) \sqrt{\frac{5 \mathrm{~T}}{M}}\right]
\end{aligned}
$$

whence

13)

$$
\frac{1.56 \times 10^{-4} \mathrm{~g} I_{s p}-\sqrt{\frac{5 T}{M}}}{\sqrt{\frac{h_{p}}{p}}-\sqrt{\frac{5 T}{M}}}
$$

From equation (9),

$$
X=\frac{M_{p}}{M_{p}+M_{c}}=\frac{\mu M_{p}}{(\mu-1) M_{0}}
$$

14)

$$
M_{p}=\frac{X(\mu-1)}{\mu} M_{0}
$$

and substituting (14) into (10) sives 
15)

$$
\begin{aligned}
M_{0} & =\mu\left[M_{f}+\frac{\beta X(\mu-1)}{\mu} M_{0}+\frac{19.3\left(10^{-6} g I_{s p}\right)^{2} \epsilon \omega}{1-X}\right] \\
& =\mu \frac{M_{f}+\frac{19.3\left(10^{-6} g I_{s p}\right)^{2} \epsilon \omega}{1-X}}{1-\beta X(\mu-1)}
\end{aligned}
$$

Other equations necessary to determine all parameters of interest either have been given above or else can be derived in obvious ways. To summarize:

$$
\begin{aligned}
& M_{p}=X\left(1-\frac{1}{\mu}\right) M_{o} \\
& M_{c}=\left(\frac{1}{X}-1\right) M_{p} \\
& N=\frac{M_{c}}{\epsilon} \\
& Y^{p}=19.3\left(10^{-6} I_{s p}\right)^{2} \frac{M_{p}+M_{c}}{N} \\
& M_{s}=\omega Y
\end{aligned}
$$

Pressure does not appear explicitly in the equations above, but it does enter through equation (13) in determining the value of $h_{p}$ for a given value of $T$. Decreasing the pressure increases the degree of ionization and the enthalpy, producing improved performance, although this benefit is offset somewhat by an increased pressure vessel weight due to the additional moles of gas contained. The effect of varying chamber pressure on $I_{5 p}$ for pure hydrogen at $6000 \mathrm{~K}$ is indicated below:

$$
\mathrm{T}=6000^{\circ} \mathrm{K}
$$

$\begin{array}{cl}p & I_{\mathbf{p p}} \\ 1000 \mathrm{~atm} & 1899 \text { gec } \\ 316 & 1440 \\ 100 & 1610\end{array}$


This improvement at lower pressures results from increased degree of dissociation, with an increase in enthalpy per unit weight due both to the additional particles and the energy of dissociation. As mentioned above, the overall effect of varying pressure will be illustrated elsewhere ${ }^{l}$. To obtain numerical examples here, a value for pressure of $316 \mathrm{~atm}$. has been chosen.

For 316 atm pressure, then, and a chamber temperature of $6000^{\circ} \mathrm{K}$ and an $\mathrm{M}$ value of 12 , values of the system parameters have been calculated for several different values of $I_{s p}$, using the same values for other parameters as given after equation 12 , and tabulated values of $h_{p}$. In addition, an estimated cost of $\$ 0.05$ million per nuclear device and an estimated freight charge of $\$ 0.40$ miliion per ton to put $M_{0}$ into earth orbit have been used to estimate total cost of the system as it would stand at the beginning of its mission:

$$
\begin{aligned}
& T=6000^{\circ} \mathrm{K} \\
& \mathrm{p}=316 \mathrm{~atm} . \\
& \mathrm{M}=12
\end{aligned}
$$

\begin{tabular}{|c|c|c|c|c|c|}
\hline$I_{s p}(\mathrm{sec})$ & 1000 & 1100 & 1200 & 1300 & 1400 \\
\hline$x$ & $.6 I$ & .70 & .79 & .88 & .97 \\
\hline$M_{0}$ (tons) & 683 & 663 & 720 & 970 & 2785 \\
\hline $\mathrm{M}_{\mathrm{c}}$ (tons) & 228 & 165 & 122 & 91 & 70 \\
\hline $\mathrm{M}_{\mathrm{p}}$ (tons) & 351 & 377 & 447 & 648 & 1990 \\
\hline$M_{s}$ (tons) & 25 & 39 & 67 & 136 & 571 \\
\hline$Y$ (tons TNT) & 1.2 & 1.8 & 3.1 & 6.4 & 26.8 \\
\hline $\mathbf{N}$ & 9120 & 6600 & 4860 & 3628 & 2790 \\
\hline Cost (mil. \$) & 729 & 595 & 531 & 569 & 1252 \\
\hline
\end{tabular}


Some prominent characteristics of the system are visible at once. The total mass has a minimum value, for a fixed $6000^{\circ}$ chamber. temperature, at an $I_{s p}$ value of slightly under $1100 \mathrm{sec}$, and a hydrogen mass fraction of around 0.7 . For mass fractions of hydrogen approaching unity, the energy per pulse becomes very large to heat the large amount of gas, and consequently the pressure vessel mass becomes high, leading to high total mass. For small propertions of hydrogen, the primary effect on mass is through a decreasing $I_{s p}$ and increasing $\mu$; leading to high total mass.

The number of pulses necessary to carry out a mission decreases with increasing specific impulse, so that if an overall figure of merit is taken to be dependent both on total mass and on the number of charges expended, the latter quantity tends to shift the optimum specific impulse and hydrogen fraction toward higher values. As an example, costs figured on the basis described above are shown in the table to have a minimum

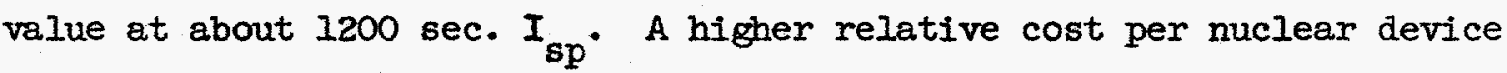
would shift the position of the minimum slowly to the right, but clearly 1t will in the nelghborhood of $1200 \mathrm{kec}$.

JWH: sd.

\section{DISTRIBUTION}
1. G. Benson
2. E. Golaberg
3. J. Hadley
4. H. Reynolds
5. H. Reynolds/File
6. H. Reymolds/File
7. S. Kellman
8. J. Foster
9. J. Radcliffe
10. T. Merkle
11. W. B. Myers

12. A. Rothman

13. G. St. Ieger-Barter

14. T. Stubbs

15. R. Duff

16. T. Wainwright

17. C. Ieith

18. R. Levee

19. J. Kane

20. W. WeIls

21. M. Mintz

22. G. Pierce 